\title{
Proliferative retinal diseases: myofibroblasts cause chronic vitreoretinal traction
}

\author{
Ronald Walshe, Peter Esser, Peter Wiedemann, Klaus Heimann
}

\begin{abstract}
Myofibroblasts are contractile cells having features intermediate between those of the fibroblast and smooth muscle. Myofibroblasts in preretinal membranes may cause retinal traction in proliferative retinal diseases. In this study, we demonstrate the presence of a chronically contractile subpopulation of myofibroblasts in pre-retinal membranes. Apha smooth muscle actin or desmin, both markers of the myogenically differentiated and chronically contractile subpopulation could be detected in a large majority of the examined membranes. Our findings may serve to explain the cellular basis of vitreoretinal traction in proliferative vitreoretinopathy and proliferative diabetic retinopathy.

(BrF Ophthalmol 1992; 76: 550-552)
\end{abstract}

Proliferative vitreoretinopathy (PVR) is characterised by the formation of preretinal membranes, the basis of which is cellular proliferation displaying analogues to wound healing and scar formation. ${ }^{\prime}$ Similar cellular membranes can be seen in proliferative diabetic retinopathy (PDR). The membrane contraction can lead to a retinal traction and the resultant detachment is a major complication of vitreoretinal surgery. Myofibroblasts cause retinal traction $^{2}$ because of the contractile properties of their cytoplasmic microfilament bundles. Myofibroblasts, having features intermediate between those of the fibroblast and smooth muscle cell, are thought to be responsible for wound contraction and the provision of tensile strength at this stage. However myofibroblasts are not one uniform cell population, for two subpopulations can be distinguished showing clear differences of myogenic differentiation and duration of contraction. ${ }^{3}$ The criterion for differential diagnosis is the molecular structure of the intermediate and microfilaments, with the cytoskeletal proteins desmin and $\alpha$ smooth muscle actin serving as markers. Myofibroblasts possessing strong myogenic differentiation contain desmin or $\alpha$ smooth muscle actin and can be shown to cause chronic contraction in pathological tissues, such as hypertrophic scar and fibromatosis. ${ }^{3}$ On the other hand, physiological myofibroblasts (for example, in the granulation tissue of normally healing wounds), which, like the pathological ones, always contain the mesenchymal intermediate filament protein vimentin, appear only transiently and cause short term contraction. They never contain desmin or $\alpha$ smooth muscle actin ${ }^{34}$

From the foregoing it should be determined if chronically contractile myofibroblasts can be identified in preretinal membranes since these

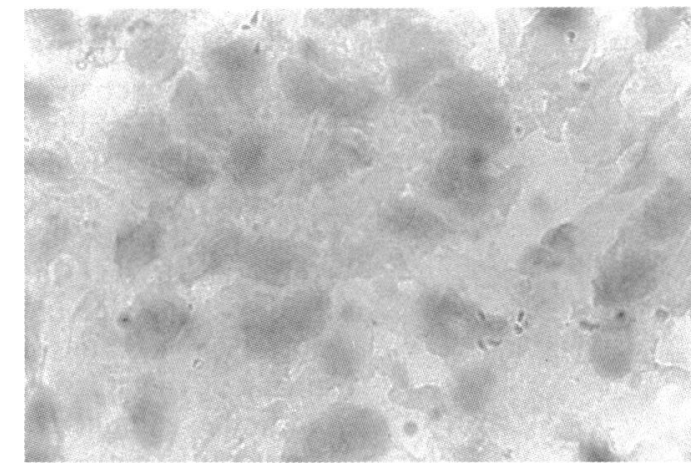

Figure 1 Negative control section treated with mouse IgG instead of specific antibody. Cell nuclei stained dark with haematoxylin and eosin. Magnification $\times 130$.

may be of significance in the mechanism of vitreoretinal traction and consequently in the prognosis.

\section{Materials and methods}

Forty five preretinal membranes from patients with eyes having traumatic PVR $(n=25)$, idiopathic PVR $(n=10)$, and PDR $(n=10)$ were obtained during vitreoretinal surgery: these were cooled to $-50^{\circ} \mathrm{C}$ in isopentane and stored at $-70^{\circ} \mathrm{C}$. Alkaline phosphatase staining was performed on 6-10 $\mu \mathrm{m}$ thick acetone-fixed cryostat sections, using as primary antibodies: monoclonal mouse anti-vimentin (code no $M$ 725, Dakopatts), monoclonal mouse anti- $\alpha$ smooth muscle actin (clone no 1A4, product no A-2547, Sigma) and monoclonal mouse anti-desmin (code no. M 724, Dakopatts).

The primary antibodies were diluted $1: 50$ with phosphate buffered saline (PBS) and $0.1 \%$ bovine serum albumin (BSA) to prevent non-specific attachments. The sections were covered with the diluted antibodies and allowed to react for 60 minutes at $20^{\circ} \mathrm{C}$.

Anti-mouse IgG (whole molecule), alkaline phosphatase conjugate $\left(\mathrm{F}(\mathrm{ab})_{2}\right.$ fragment of affinity isolated antigen specific antibody, product no A-0532, Sigma) was used as secondary antibody in a dilution of 1:50 and incubated for 45 minutes at $20^{\circ} \mathrm{C}$. The substrate was made up of: naphthol AS-MX phosphate, free acid (product no N-4875, Sigma), $12 \mathrm{mg}$,

Table 1 Distribution of the cytoskeletal proteins vimentin $\alpha$ smooth muscle actin, and desmin in 45 preretinal membranes

\begin{tabular}{llll}
\hline & $\begin{array}{l}\text { Idiopathic } \\
P V R(\%) \\
(n=10)\end{array}$ & $\begin{array}{l}\text { Traumatic } \\
P V R(\%) \\
(n=25)\end{array}$ & $\begin{array}{l}P D R(\%) \\
(n=10)\end{array}$ \\
\hline $\begin{array}{l}\text { Vimentin } \\
\alpha \text { smooth } \\
\begin{array}{l}\text { muscle actin } \\
\text { Desmin }\end{array}\end{array}$ & 100 & 100 & 100 \\
\hline
\end{tabular}


Figure 2 Alkaline phosphatase staining for a smooth muscle actin in a preretinal membrane from a patient suffering from idiopathic PVR. Arrows indicate linearly arranged microfilament bundles

which are $\alpha$ smooth muscle actin positive.

Counterstaining with

haematoxylin and eosin shows cell nuclei (some marked by stars).

Magnification $\times 130$

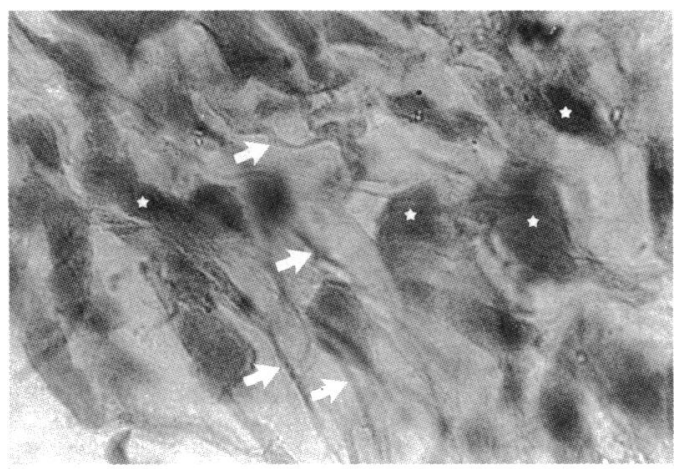

Fast Red TR (CI 37085, product no F-2768, Sigma), $5 \mathrm{mg}$, and $4900 \mu \mathrm{l}$ TRIS buffer, $0.2 \mathrm{M}$, pH 8.2. Negative controls (Fig 1 ) were performed on all sections by substituting mouse IgG (product no I-5381, Sigma) for the primary antibodies. Positive tissue controls for the vimentin, $\alpha$ smooth muscle actin and desmin antibodies were obtained by staining the muscular tunic of human small intestine.

\section{Results}

The results are summarised in Table 1 .

Positive labels for vimentin were observed in all membranes. Alpha smooth muscle actin (Fig 2) was found in $90 \%$ of membranes of patients suffering from idiopathic PVR and PDR and in $80 \%$ of membranes of those with traumatic PVR.

Desmin (Fig 3) was identified in $30 \%$ of slides of idiopathic PVR, $44 \%$ of slides of traumatic PVR, and in $60 \%$ of cases of PDR.

\section{Discussion}

The aim of this study was to draw conclusions about vitreoretinal traction from the occurrence of the cytoskeletal proteins $\alpha$ smooth muscle actin and desmin in preretinal membranes, vimentin serving to identify mesenchymal cells.

Firstly, it must be shown that cells displaying $\alpha$ smooth muscle actin and desmin actually represent myofibroblasts. A safe attribution could be made only on the basis of ultrastructural examinations, but in this context the attribution is compelling for the following reasons; (a) $\alpha$ smooth muscle actin and desmin, which are normally present in smooth or striated muscle only, are characteristic of chronically contractile subpopulations of myofibroblasts. ${ }^{3}$ (b) Myofibroblasts have been identified by electron microscopy in PVR membranes. ${ }^{5}$ (c) Alpha smooth muscle actin and desmin are atypical of

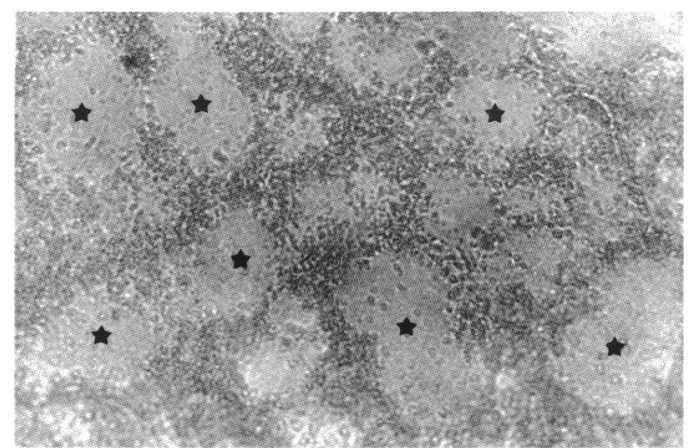

any other cell types present in preretinal membranes: retinal pigment epithelium cells, ${ }^{6}$ ? macrophages ${ }^{89}$ glial cells, ${ }^{10}$ and microglial cells. ${ }^{11}$ Therefore, it can be deduced from the distribution of the proteins in PVR and PDR membranes that chronically contractile myofibroblasts with a strong myogenic differentiation appear in the majority of the examined membranes.

Thorough biochemical and ultrastructural examination of these cells resulted in the important finding that myofibroblasts with a strong smooth muscle differentiation are never found in physiological tissues such as physiological granulation tissue and normally healed scar. However they are present in pathological tissues displaying chronic retraction such as hypertrophic scar, fascial and musculoaponeurotic fibromatosis, and intra-abdominal fibromatosis (Gardner's syndrome). ${ }^{3}$ For this reason the cytoskeletal proteins used in this study are considered by Skalli et al $^{3}$ to be markers both with respect to the prognosis of diseases and the effectiveness of treatment.

We believe that our findings can serve to explain the mechanism of vitreoretinal traction in proliferative retinal diseases. Theories of traction so far suggested included cell contraction, ${ }^{2}$ cell mediated gel contraction based on the activity of retinal epithelium pigment cells, ${ }^{12}$ and hypocellular gel contraction based on the organisation and compaction of collagen fibrils causing anterior loop traction. ${ }^{13}$ In our view the presence of myogenically differentiated myofibroblasts in preretinal membranes suggests that cellular (that is, myofibroblastic) contraction does play an important role in the development of vitreoretinal traction.

The distinction between myofibroblastic subpopulations also creates a biochemical basis for examining the different biological behaviour of cells and tissues towards stimulants and inhibitors. It could be shown that various tissues containing myofibroblasts show different patterns of reaction towards substances which cause contraction of smooth muscle cells. ${ }^{1416}$ Such a physiological differentiation of myofibroblasts may, just as the above criterion of chronic contraction, be correlated with the molecular composition of cytoskeletal proteins. Finally, the same could hold for the effectiveness of substances inhibiting the proliferation and contraction of preretinal tissues. Examinations of whole membranes of known myofibroblastic differentiation with respect to their contraction behaviour towards various physiological and pharmacological agents (for example, serotonin) might therefore yield pertinent information.

The authors thank Miss Beatrix Martiny for excellent technical assistance.

This work was supported by the Retinovit Foundation and Deutsche Forschungsgemeinschaft DFG grant Wi 880/3-2 to PW.

1 Weller M, Wiedemann P, Heimann K. Proliferative vitreoretinopathy - is it anything more than wound healing vitreoretinopathy - is it anything more than wound

2 Ussman JH detachment: a cell mediated event. Arch Ophthalmol 1981; 99: 869-72.

3 Skalli O, Schürch W, Seemayer T, Lagacé R, Montandon D, Pittet B, et al. Myofibroblasts from diverse pathologic settings are heterogeneous in their content of actin isoforms and intermediate filament proteins. Lab Invest 1989; 60: $275-85$. 
4 Skalli O, Gabbiani G. The biology of the myofibroblast relationship to wound contraction and fibrocontractive diseases. In: Clark RAF, Henson PM, eds. The molecular and cellular biology of wound repair. New York: Plenum, and cellular biolo

5 Cleary PE, Minckler DS, Ryan SJ. Ultrastructure of traction retinal detachment in rhesus monkey after a posterior penetrating ocular injury. Am F Ophthalmol 1980; 90: 829-

6 Machemer R, Laqua H. Pigment epithelium proliferation in retinal detachment (massive periretinal proliferation). $A m \mathcal{F}$ Ophthalmol 1975; 80: 1-23.

7 Hiscott PS, Grierson I, McLeod D. Retinal pigment epithelia cells in epiretinal membranes: an immunohistological study. Brf Ophthalmol 1984; 68: 708-15.

8 Kampik A, Kenyon KR, Michels RG, Green WR, Cruz ZC de la. Epiretinal and vitreous membranes. Comparative study of 56 cases. Arch Ophthalmol 1981; 99: 1445-54.

9 Miller B, Miller H, Patterson R, Ryan SJ. Retinal wound healing. Cellular activity at the vitreoretinal interface. Arch Ophthalmol 1986; 104: 281-5.

10 Hiscott PS, Grierson I, Trombetta CJ, Rahi AHS, Marshall I,
McLeod D. Retinal and epiretinal glia - an immunohistochemical study. Brf Ophthalmol 1984; 68: 698-707.

11 Weller M, Esser P, Heimann K, Wiedemann P. Retinal microglia: a new cell in idiopathic proliferative vitreoretinopathy? Exp Eye Res 1991; 53: 275-81.

12 Glaser BM, Cardin A, Biscoe B. Proliferative vitreoretinopathy: the mechanism of development of vitreoretinal traction. Ophthalmology 1987; 94: 327-32.

13 Blumenkranz MS, Hartzer MK. Pharmacologic management of PVR. In: MacKenzie Freeman H, Tolentino FI, eds. Proliferative vitreoretinopathy $(P V R)$. New York: Springer, 1988: 81-7.

14 Majno G, Gabbiani G, Hirschel BJ, Ryan GB, Statkov PR. Contraction of granulation tissue in vitro: similarity to smooth muscle. Science 1971; 173: 548 .

15 Gabbiani G, Hirschel BJ, Ryan GB, Statkov PR, Majno G. Granulation tissues as a contractile organ: a study of structure and function. $\mathcal{F} \operatorname{Exp}$ Med 1972; 135: 719.

16 Evans JN, Kelley J, Low RB, Adler KB. Increased contractility of isolated lung parenchyma in an animal model of pulmonary fibrosis induced by bleomycin. Am 7 Resp D is 1982; monary 